\title{
The Formation of a Dispersed Gas System in the Flotation Cells
}

\author{
E.V. Alekseev * \\ Moscow state university of civil engineering, Moscow, Russia.
}

\begin{abstract}
The use of flotation methods for wastewater treatment is due to their advantages in comparison with other methods of gravity separation, for example, sedimentation. The advantages of flotation water treatment methods include the high speed of the separation process, the ability to extract impurities that are close in density to water, environmental friendliness. Flotation methods are based on adsorptive bubble separation processes. Accordingly, the performance of a particular flotator directly depends on the conditions for the implementation of these processes in a particular flotation cell. The aim of the research was to study the relationship between the dispersed gas phase (DGP) and the ratio of the geometric dimensions of the flotation cells based on the proposed shape indicator of the flotation cell. Studies performed on the experimental model of the flotator have established a significant influence of the shape indicator of the flotation cell on such important indicators of the adsorptive bubble separation processes as gas-filling and the DGP floating speed. The evaluation of different forms of flotation cells, in relation to the properties of extracted bubble-particle complexes is given.
\end{abstract}

\section{Introduction}

Flotation separation processes are widespread for solving various problems of extracting water impurities [1-2]. These processes are successfully used both for purification of wastewater of different formation conditions and for sludge separation [3-5]. Flotation is used to purify water from dispersed liquid and solid impurities, surfactants as a primary stage or to separate additionally added materials, such as coagulants, sorbents and others.

Flotation water treatment methods are classified as gravity separation processes. Unlike sedimentation tanks, the gravitational separation of pollutants is carried out in the form of a complex of particles with bubbles of a dispersed gas phase (DGP). The advantage of the flotation method is the removal of pollutants particles, which have a density greater than or less than the density of water. Including particles with a density close to the density of water, for which gravitational separation at rest is ineffective [6-7]. Flotation wastewater treatment is based on adsorptive bubble separation processes [8]. The efficiency of the flotation process depends on the conditions of adsorption interaction of pollutants with

\footnotetext{
*Corresponding author: AlekseevE@mgsu.ru
} 
dispersed gas bubbles, the conditions for the formation of bubble-particle complex, and the hydrodynamic conditions for their floating on the open surface of the flotation cell [9].

The patterns of adsorption interaction of solid or liquid particles with the surface of gas bubbles at the gas-water interface have been studied by many authors of flotation works for mineral processing, purification of natural and waste waters, and other purposes.

Much less in the works is reflected the geometric parameters of flotation cells on the flotation separation process. However, there is no doubt that the shape of the geometric volume of the flotation cell affects the motion of the DGP carrying particle-bubble aggregates. The most favorable conditions for flotation separation can be achieved in a flotation cell corresponding to the best conditions for the movement of DGP and bubbleparticle complexes.

The purpose of the research was to study the relationship of DGP indicators with the ratio of the geometric dimensions of flotation cells, to use the results in the designing and modelling flotators. The research objectives included the development of a shape indicator of the flotation cell, the justification of the adopted DGP indicators and the experimental study of their relationship.

\section{Materials and methods}

The first stage of the research included the formation of an indicator characterizing the shape of the flotation cell. Assessment of the flotation cell shape from the position of its influence on the hydrodynamic structure of the flotation space should reflect indicators, characterizing the ratio of the main geometric dimensions of the chamber in the active zone of the adsorptive bubble separation. For the geometric description of the camera, an expression of the similarity invariant of the form is accepted:

$$
K_{f}=\frac{L_{(H)}}{L_{(S)}},
$$

where $L_{(H)}$ and $L_{(S)}$ - vertical and horizontal scale simulations of a flotation cell.

As the "original" geometric shape in the formation of shape indicator adopted cube, for which

$$
L_{(H)}=H ; \quad L_{(S)}=a,
$$

where $H$-camera height; $a$ - the length of the edges of the cube.

Since $a=4 S / p$, expression (1) takes the following form:

$$
K_{f}=\frac{H \cdot p}{4 S},
$$

where $\mathrm{S}$ - area of the base; $p$ - perimeter of the base..

The simplex by expression (2) was adopted as an indicator for evaluating the shape of the flotation cell in experimental studies.

The second stage of the research consisted in the selection and justification of DGP parameters in flotation cells accepted for experimental study.

Gas-filling of the flotation cell is one of the most important indicators characterizing the amount of dispersed gas in water [10]. The amount of gas-filling is affected by the size of gas (air) bubbles in the water, their floating speed, the geometric dimensions of the flotation cell, and the consumption of the incoming gas. 
Gas-filling is the volume of dispersed gas in dynamic equilibrium in the flotation cell. By definition, the relative gas filling value $\mathrm{j}$ is the ratio of the volume of gas $W_{b}$, distributed in the liquid phase in the form of bubbles to the volume of the gas-liquid mixture $W_{m}$ :

$$
\varphi=\frac{W_{b}}{W_{m}+W_{b}}
$$

With a constant cross section of the flotation cell, gas-filling can be expressed through the ratio of heights:

$$
\varphi=\frac{\Delta H}{H+\Delta H},
$$

where $\mathrm{D} H$ - increased liquid level in the flotation cell during gas passage, $\mathrm{m} ; H$ - liquid height without gas supply, m.

In the steady state, the volumes of the gas and liquid phases are in dynamic equilibrium. In this case, the volume of the gas phase distributed in the liquid will be equal to:

$$
W_{b}=Q_{g} \bar{\tau}
$$

where $Q_{g}$ - flow rate of the incoming gas, $\mathrm{m}^{3} / \mathrm{s} ;{ }^{\prime} \mathrm{t}$ - average period of the gas phase in the liquid, $s$.

Expression (5) can be represented as equality:

$$
\Delta H \cdot S=Q_{g} \bar{\tau}
$$

where $S$ - cross section of the flotation cell, $\mathrm{m}^{2}$.

From where

$$
\bar{\tau}=\frac{\Delta H \cdot S}{Q_{g}}
$$

Formula (7) makes it possible to experimentally determine t by change in the liquid level in the flotation cell, since $S$ and $Q_{g}$ can be measured.

Replacing $S / Q_{g}$ with $1 / V$, obtained the expression for the average phase contact period:

$$
\bar{\tau}=\frac{\Delta H}{V},
$$

where $V$ - gas flow through the full cross section of the flotation cell, $\mathrm{m}^{3} /\left(\mathrm{m}^{2} \times \mathrm{s}\right)$

On the other hand, the period of the gas phase in the flotation space is due to the floating period of bubbles:

$$
\bar{\tau}=\frac{H+\Delta H}{\bar{U}}
$$

where $\bar{U}$ - average collective floating speed of gas bubbles, $\mathrm{m} / \mathrm{s}$.

Equating expressions (8) and (9), acquire: 


$$
\frac{\Delta H}{V}=\frac{H+\Delta H}{\bar{U}}
$$

where we get the expression of the amount of gas-filling in dynamic equilibrium conditions:

$$
\varphi=\frac{V}{\bar{U}}
$$

Therefore, theoretically, the amount of gas-filling reflects the relationship between the gas flow in the cross section of the flotation cell and the average rate of collective floating of gas bubbles. Experimental determination of the average DGP floating speed is a complex process. However, using formula (10), this problem can be solved quite simply by measuring the gas-filling and gas flow:

$$
\bar{U}=\frac{V}{\varphi}
$$

The third stage included experimental studies, that were carried out on the setup shown in Fig. 1

The model of a prism-shaped flotation cell with dimensions in plan of $0,15 \times 0,15 \mathrm{~m}$ and height $1,8 \mathrm{~m}$. At the lower part placed electrons, which are connected to a direct current source.

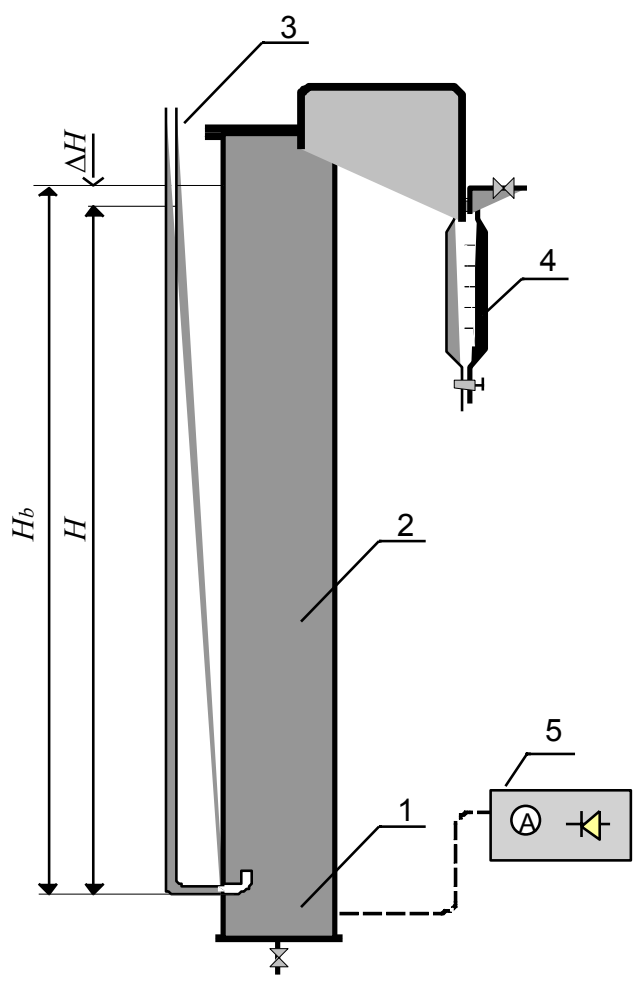

Fig. 1. Scheme of the experimental setup: 1 - electrode package; 2 - flotation cell; 3 - piezometer; 4 measuring vessel to control the gas flow; 6 - control power supply of the unit. 
To obtain DGP in the experiments, the electrochemical method of obtaining gas dispersion was used. The electrochemical method to produce a gas dispersion in water is convenient, allowing to widely vary the amount of gas dispersion and doesn't change the amount of water in the flotation cell. The gas flow rate was $2.55 \mathrm{dm} 3 / \mathrm{h}$. Relative gas consumption $-113 \mathrm{dm} 3 /(\mathrm{m} 2 \times \mathrm{h})$ for horizontal composition of the flotation cell.

The water level heights in the installation $(\mathrm{H})$ without gas dispersion in the experiments were taken: $0.15 ; 0.5 ; 1.0 ; 1.5$; and $1.6 \mathrm{~m}$. This corresponded to the values of the shape indicator of the flotation cell $\left(\mathrm{K}_{\mathrm{f}}\right): 1.0 ; 3.3 ; 6.7 ; 10.0$ and 10.7 .

An increase in the level of water containing a gas dispersion during the operation of the electrode package $\left(\mathrm{H}_{\mathrm{b}}\right)$ was recorded by the differences in height, in the flotation cell and in the piezometer $(\mathrm{DH})$.

The amount of gas-filling was determined by the formula (4) for the given values of the shape indicator and the corresponding heights of the water level.

\section{Results and Discussion}

The experimental dependence of gas-filling from the shape of the flotation cell is shown in Fig. 2.

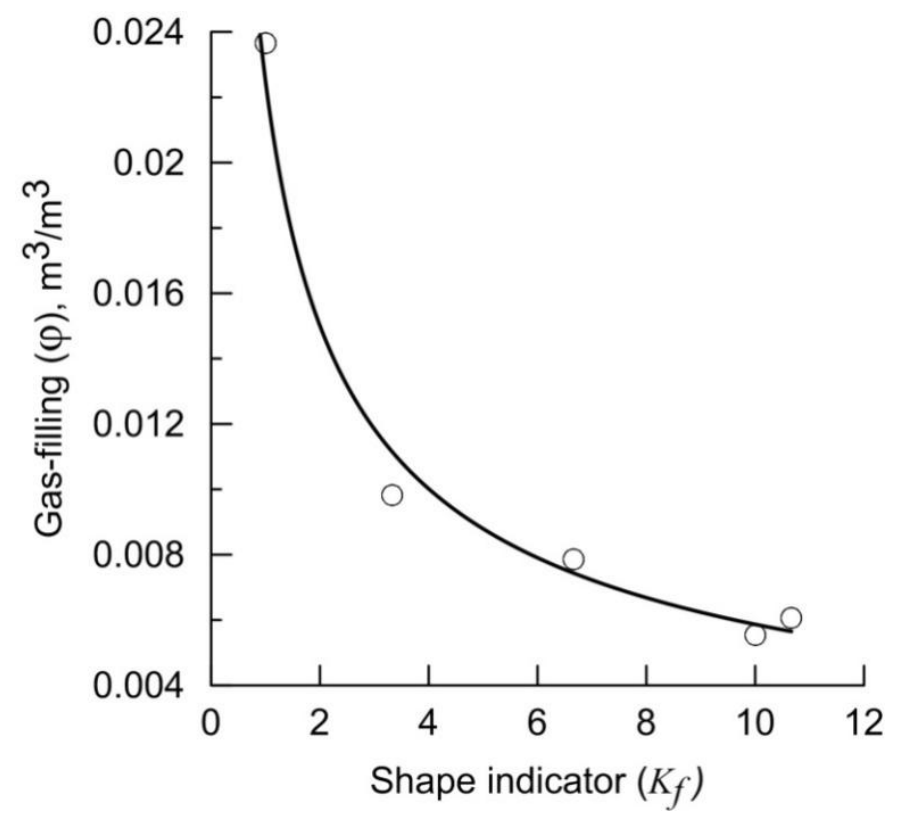

Fig. 2. The influence of the shape indicator of the flotation cell on the amount of gas-filling

Processing the results of the influence of the shape of the flotation cell on gas-filling using the formula (11) made it possible to obtain the dependence of the average floating speed of the dispersed gas phase, that shown in Fig. 3. 


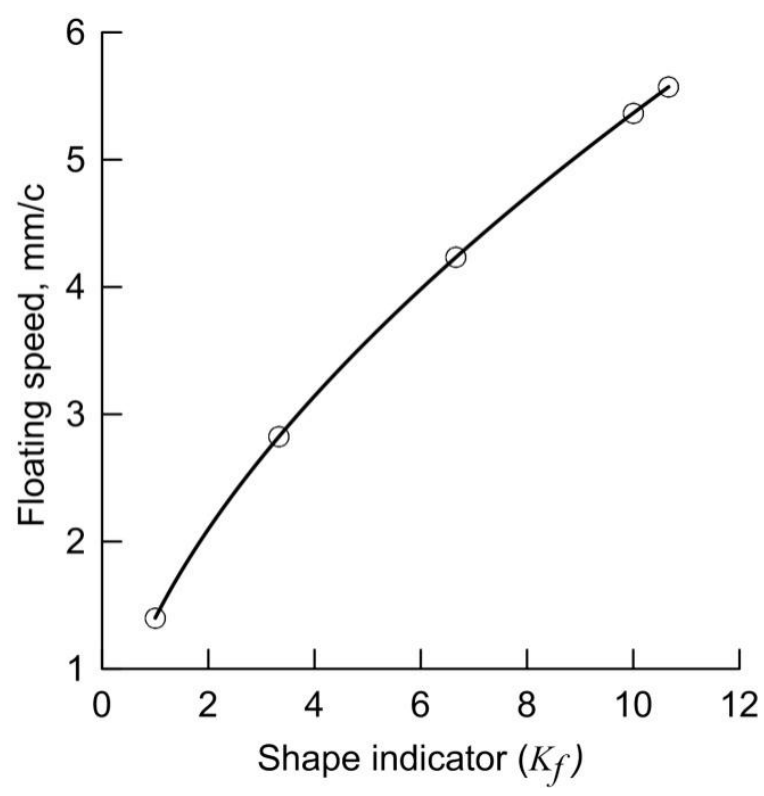

Fig. 3. The influence of the shape indicator of the flotation cell on the value of the average floating speed of the gas dispersion

The obtained dependences reflect the hydrodynamic conditions for the rise of a dispersed gas phase in flotation cells with different aspect ratios. In a flotation cells of shallow depth, the gas dispersion moves to an open surface with velocities close to the velocity of its own gas bubbles. With a significant content of microdispersion of gas bubbles and with an increase in depth, the movement in the flotation cell acquires the character of convective flow. The intrinsic velocity of microbubbles in water remains much lower than the velocity of the volume of water filled with dispersed gas. This is leading to intensive mixing of the gas dispersion in the flotation cell. The floating speed of separate gas bubbles also changes as a result of coalescence. The result is a faster movement of the gas phase to the open surface of the flotation cell. This is typica for vertical flotation cells $\mathrm{K}_{\mathrm{f}}<3$ (Fig.2).

A further increase in the depth of the flotation chamber $\left(K_{f}>3\right)$ leads to gradual decrease and stabilization of gas-filling. This is due to the occurrence of downward degassed water flows in cramped conditions of the flotation cell. The negative effect of downward flows on the flotation separation process is in reduced gas-filling in the flotation cell, an increase of the mixing intensity, in destruction of some bubble-particle complexes, in partial return of the extracted pollutants to the treated water zone and in deterioration its quality.

\section{Summary}

The effectiveness of flotation water treatment includes two aspects - the duration of the process and the quality of the purified water. The design of flotators or the selection of suitable equipment must be carried out with taking into account the physicochemical and structural-mechanical features of the extracted bubble-particle complex. The usage of a geometric simplex in studies made it possible to evaluate the influence of the shape of the flotation cell on the formation and movement of gas dispersion.

Vertical flotation cells provide higher separation rates for bubble-particle complex with strong bonding to the dispersed gas phase. In this case, a large distance between the 
position of the separation surface of the flotation sludge and the lower part of the flotation cell, where the purified water is discharged (the length of the separation path) helps to increase the efficiency of water treatment. The disadvantage of a vertical flotation cell is a more intense movement of microdispersion of gas bubbles. This leads to the destruction of bubble-particle complex with low aggregate stability.

The horizontal flotation cells $\mathrm{K}_{\mathrm{f}}<1$ and the flotation cells $\mathrm{K}_{\mathrm{f}}=1$ are characterized by the lowest velocities of microdispersion of gas bubbles and short separation path. This has a positive effect on separation of aggregative unstable bubble-particle complexes, reduces the stay period of water in the flotation cell. However, the short length of the separation path increases the possibility of insufficiently purified water and fragments of sludge entering the outlet of purified water.

The obtained results have a great practical importance when choosing the type of flotation cell for water purification from pollutants, that have different adsorption capacity and aggregative stability in the composition of gas bubbles microdispersion in water.

\section{References}

1 C.N.Tian, L.I. Jie, Y. E. Wang, et al., Application of shallow air flotation for water treatment, J.Industrial Water \& Wastewater, v..2(1), pp.17 - 20 (2013)

2 R.Sarbu, C. Badulescu and L. Toth, Waste water treatment by flotation, Acta Montanistica Slovaca Ročník, v. 10, pp. 97-99 (2005)

3 J. P. Bogacki, P. Marcinowski, J. Naumczyk, P. Wiliński, Cosmetic wastewater treatment using dissolved air flotation, Archives of Environmental Protection, v. 43(2), pp. 65-73

4 E.V. Alekseev, Abatement of environmental pollution by effluents of textile industry, Pollution Research, v. 37(1), pp. 278-284 (2018)

5 M. Zlokarnic, Separation of activated sludge from purified waste water by induced air flotation, Water Research, v. 32(4), pp.1095-1102 (1998)

6 B. J. Bradshaw, In Encyclopedia of Separation Science; Wilson, I.D., Ed., Academic Press: San Diego, pp.1455-1572 (2000)

7 R. Lemlic, Adsorptive bubble separation techniques: Foam fractionation and allied techniques, Industrial \& Engineering Chemistry, 60, p.16 (1968)

8 M.Prasad, A.K.Majumder, T.C. Rao, Reverse Flotation of Sedimentary Calcareous/Dolomitic Rock Phosphate Ore, Minerals \& Metallurgical Processing, v. 17(1), pp 49-55 (2000)

9 T.Zabel, The advantages of dissolved-air flotation for water treatment. J Am, Water Works Assoc., 77 (5), pp 37-41 (1985)

10 P.Stevenson, Li. Xueliang, Foam Fractionation. Principles and Process Design, Boca Raton CRC Press, p. 206 (2014) 